\title{
Examining Urban Dwellers' Perception of Built Environmental Issues as Framework to Build Collective Consciousness in Indian Cities
}

\author{
Susan Maria Thomas
}

School of Planning and Architecture, Bhopal, India

\begin{abstract}
The increase in urban population by $1 \%$ every year, especially along the fringes of cities has put pressure on the built and unbuilt environment in India. A study estimates 6,95,000 premature deaths in 2010 due to continued exposure to outdoor particulate matter and ozone pollution in Delhi, increasing pressure on governing bodies to provide 'green' solutions to address the poisonous air. The choice of where to live in cities is limited and the homogeneity of the built spaces dissolves practice of innovative options. A discussion on an active participation in knowing the built environment is increasing. Under the UNESCO Agenda 21, an active local participation in knowing the built environment is encouraged. A lack of awareness infiltrates the realms of the urban society who have very less 'say' to the decision making of these built spaces. What ensues is the repetition of an unsustainable design language. However, their choices are in turn influenced by design choices made by the urban dwelling public in cities. The paper explores which aspects of the built environment is understood by an urban dweller by means of a public survey. The gap in perception of built environment issues based on literature is identified and a critical need for knowledge dissemination is recognized. Various techniques that would facilitate an effective learning among the public is explored and the recognition of a platform that allows the same is found to be imperative in Indian cities.
\end{abstract}

Keywords: built environment, awareness, community knowledge, environmental governance, perception, exchange

\section{Introduction}

India has seen a growth of urbanization from $25.7 \%$ (1991) to $27.82 \%$ (2001) and to $31.14 \%$ (2011). This is a rise of $3.3 \%(2001-2011)$ in comparison to the rise of $2.1 \%(1992-2001)$. Also, the projected growth for 2015 - 2020 is a 2.37\% (Affairs, 2019). An unprecedented conurbation has put pressure on resources both tangible and intangible. Hence, the 'built environment' which are settings for human comfort such as parks, buildings including supporting infrastructure require critical understanding among the public (Services, 2006).

The current study is intended as a strategical step for achieving the vision of UN Sustainable Development Goals (SDGs) by capacity building and public participation for urban dwellers in Indian cities. Most studies about the built environment in India has focussed on the user experience and perceptions of urban public spaces or parks. Various studies relating to the impact of the built environment has also been made. The current paper approaches the user- perception of the impact of built and open spaces based on traditional knowledge and technological advancements. The gaps that arise in their understanding based on literature data are understood through survey. Further, methods to have inclusive capacity building among individuals and community in the society through information dissemination is explored in detail.

A methodology is formulated where effective knowledge dissemination techniques would attempt to fulfil the gaps in the user perception. The layout of this study is shown schematically in Figure 1. 


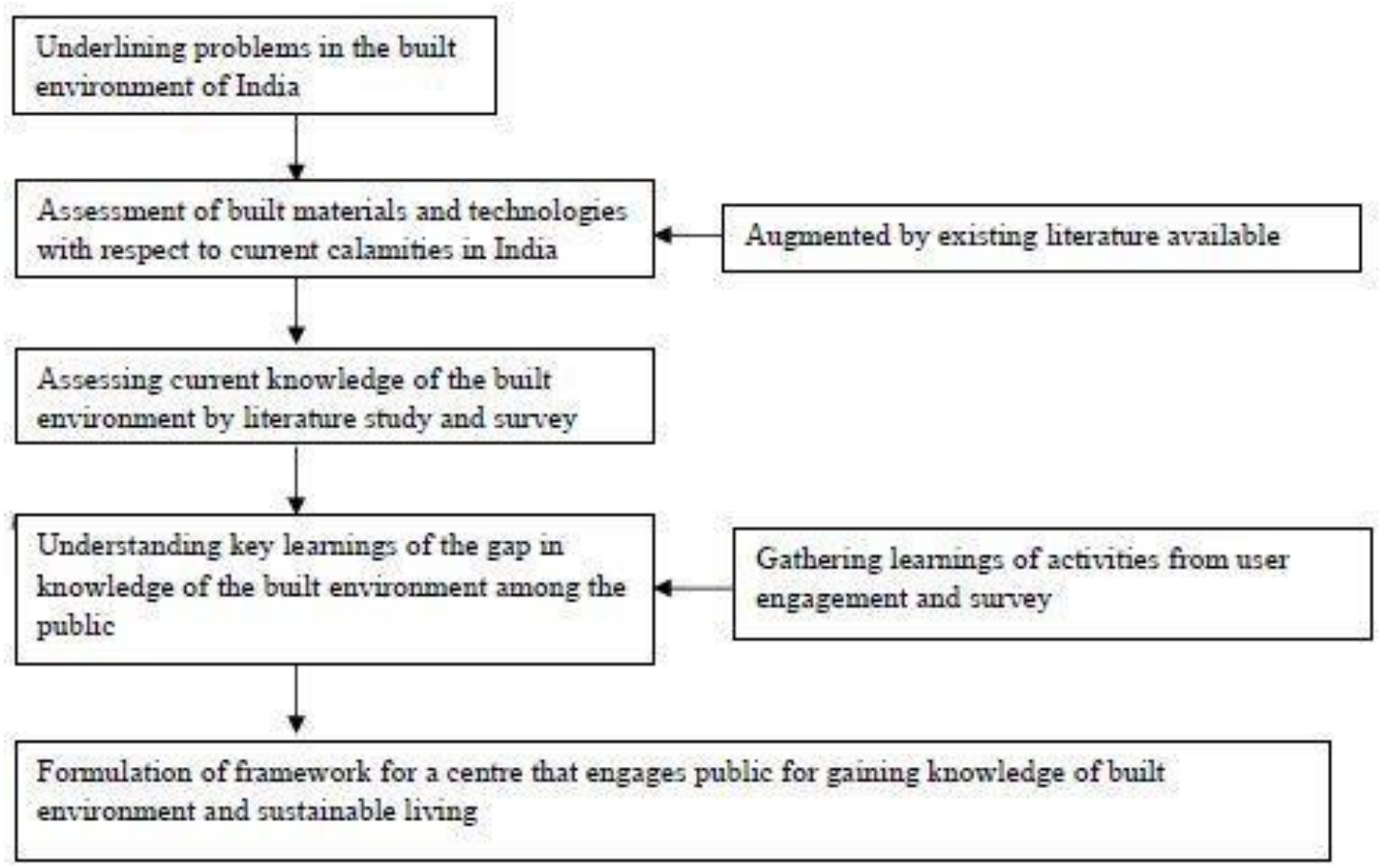

Figure 1 Methodology of study

\section{Environmental Issues due to Urbanization}

Population growth in major Indian cities such as Delhi and Mumbai would include the major global urban dwellers by 2025 (Kumar \& Singh, 2017). According to World Bank study, productivity losses and healthcare fees from pollution, cost India up to $8.5 \%$ of Gross Domestic Product (GDP). Some of the severe cases of environmental degradation due to this rapid urbanization include the Air Quality Index (AQI) hitting 469 in parts of Delhi in December 2017 (ENVIS Center on Human Settlement's, 2018). Similarly, Delhi's readings of PM 2.5 exposure has gone above 1000 micrograms per cubic meter when even crossing 300 micrograms per cubic meter is hazardous. With the construction industry contributing to $30 \%$ of air pollution in Delhi, the need to repress the harmful side effects from it is necessary. Within the larger umbrella of built environment, the notions and pragmatics of its setting is paramount to be understood by all involved in the construction process including the common man.

\section{The reserve of ecological design in traditional Indian settlements}

Majority of the cost of construction of a built mass weighs on the building materials used. Moreover, they are responsible for various direct and indirect impact on the environment such as carbon footprint, harmful gases and so on. India's history of traditional knowledge of building, is a large reserve for ecological design. Taking example of a bamboo structure, the varieties of which is diverse, the use of it as a structurally stable building material was widespread once. Some of the examples include:

- In its most abundant habitat, northeast states of India such as Assam and Meghalaya, use it for plinths, roof, walls and fences.

- Used in floodplains of Bihar, Bengal and Orissa in tribal communities and have withstood severities for 70-80 years (Manjunath, 2015).

- In southern states, bamboo was used with other materials such as mud in wattle and daub construction. 
Other materials such as lime were used as both structural and non-structural purposes. Some of the evidences can be seen in Mughal and Rajasthan-i paintings that capture the grandeur of the buildings. It is also one of the major element in conservation projects today. Archaeological evidences show that dwellings of unbaked earth made from alluvial soil was also used (Guillaud \& Houben, 1994). In northern India, earth was the most abundant material and applications are found on Buddhist monasteries as old as 100-200 years (Gupta and Singh, 1987). With the increase of natural disasters in the country and globally, the resilience learnt from vernacular building construction is a goldmine.

Traditionally, these knowledge of construction was passed on among generations, especially among the mason families of a community. Traditional knowledge systems have also been relevant in discussions such as that of the Rio Convention 1992, UNESCO 2000, Food and Agricultural Organization and so on. Biological Conservation and techniques for the same are also strong knowledge reserves among indigenous communities of tribal communities. Contemporary methods for a similar knowledge dissemination of construction techniques as well as a method for learning about the traditional knowledge systems would improve capacity building and resilient building knowledge for the future generations.

Moreover, scientific comparisons of contemporary and traditional building materials in the basis of carbon dioxide emissions and embodied energy, show the significance of traditional materials over newer technologies. A study done by Braganca and Mateus (2011) as well as Berge (2009) is summarized in Figure 2. The study indicates the high embodied energy and global warming potential in conventional building materials such as steel and concrete in comparison with vernacular building materials such as rammed earth, timber and straw. Considerable energy savings can be achieved by studying the research done on materials that are used in urban areas especially for commercial and housing purposes.

Research shows that pertaining to reinforced concrete buildings, the amount of carbon dioxide varies and is highest for aluminum, steel, glass, stone and concrete followed by brick and the least being in cement mortar (Sagheb, Vafaeihosseini, \& Ramancharla, 2011). With the cost of cement reducing, the usage of it as a building material is increasing. In the fringes of the urban areas, the use has infiltrated into the rural areas under the perspective of 'pucca' homes. The overall impact on the environment with regard to the material extraction, manufacture and distribution i.e. carbon dioxide emissions are determinants of the sustainability in mega -cities. In countries such as New Zealand, a detailed analysis of net carbon emissions from the construction industry infer that alternative building materials such as wood instead of steel, concrete and aluminium need to be adopted (H. Buchanan \& Honey, 1994). The need of this knowledge being available and accessible can inform citizens of the persistent need of practicing sustainable living choices. 


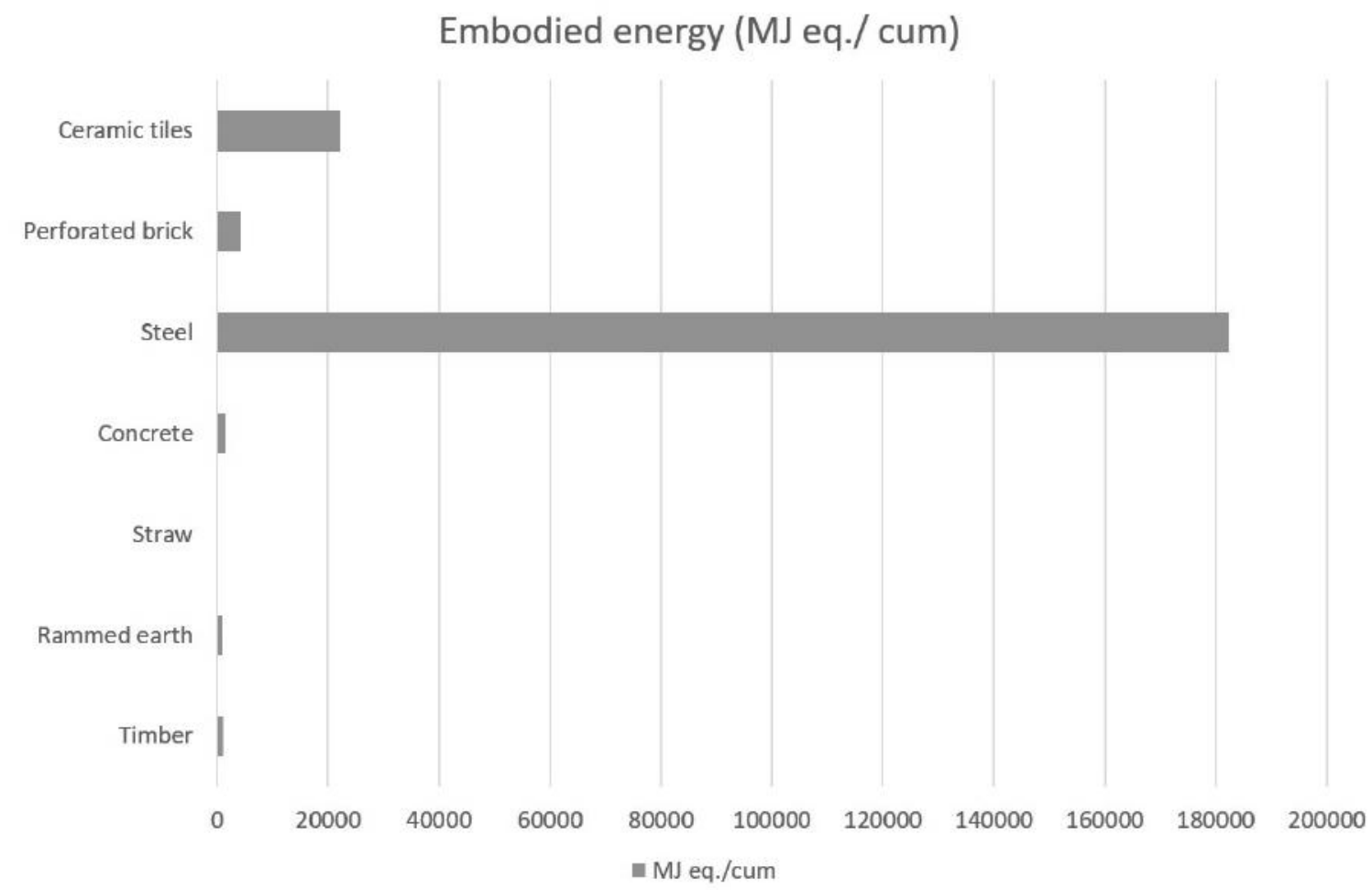

\section{Global Warming Potential (kg CO2 eq./cum)}

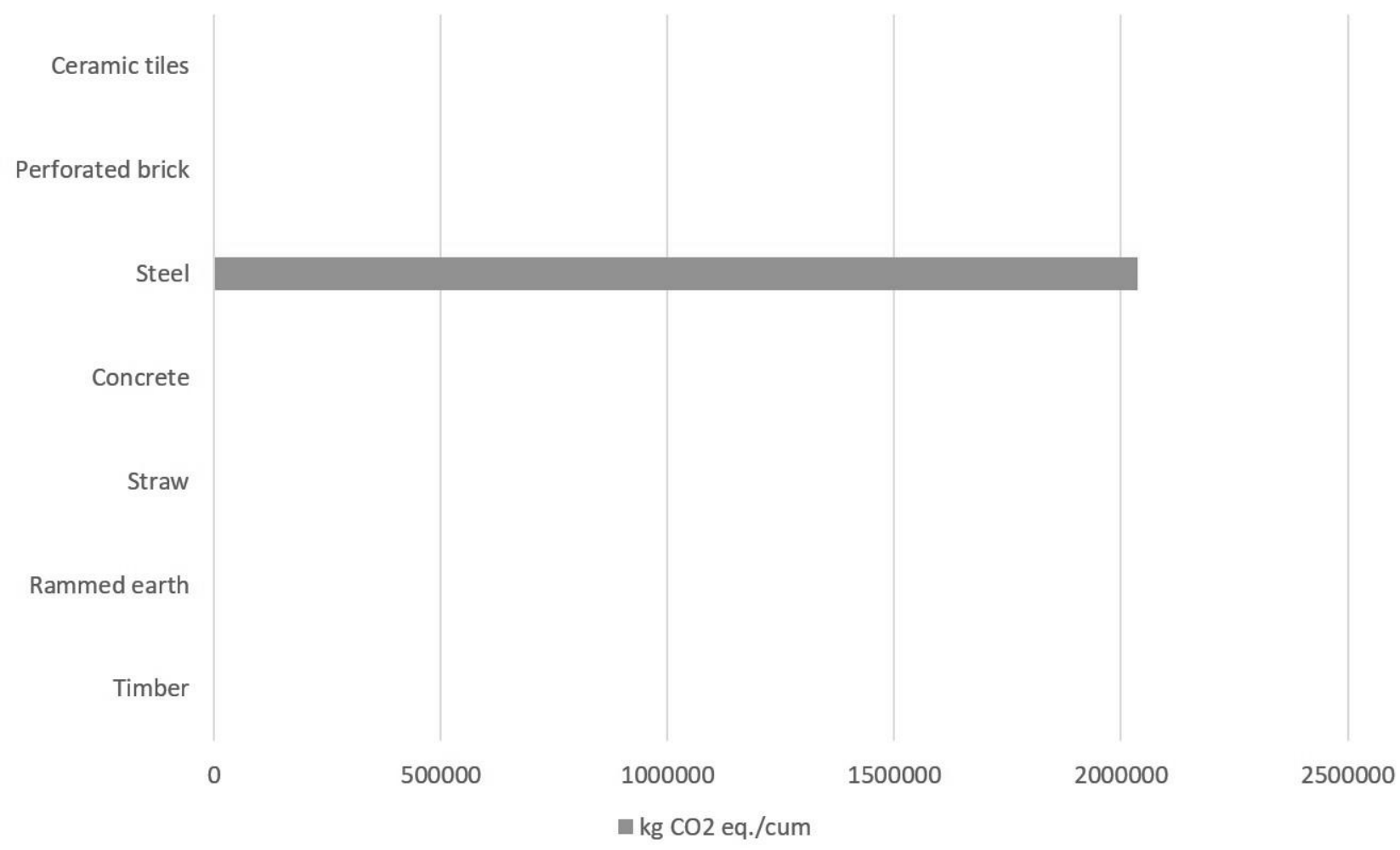

Figure 2 Comparison of embodied energy and global warming potential of various building materials (based on study by Braganca and Mateus, 2011 and Berge, 2009) 


\section{Green Infrastructure and open space study in India - a brief}

A part of studying the built environment of a city is to include the open green spaces and the infrastructure invested to improve the quality of human settlement. According to the Forest Survey of India (FSI) 2017 report, the total tree cover of India is $2.85 \%$ of its total geographical area (FSI, 2017). Further, research shows that in Delhi, 18,000 parks constitute 20\% of green cover, according to Municipal Coorporation of Delhi. This is further planned to rise 30\% in the future (Bhalla \& Bhattacharya, 2015). The benefits of an urban tree over are many including air filteration, micro climate regulation, urban drainage by countering soil erosion etc. They are strategies to cool down urban heat islands and also storage sites for carbon dioxide (McPherson \& Simpson, 1999). With major urban sprawl, the land available for open green spaces in the form of parks and other green spaces are reducing. The following table (Table 01) illustrates the per capita green space in each city. Delhi records the highest percentage of tree cover, whereas it is considerably low in West Bengal.

Table 1 Tree cover estimates (Forest Suvey of India, 2017)

\begin{tabular}{llll}
\hline $\begin{array}{l}\text { Tree cover estimates of States } \\
\text { of India }\end{array}$ & Geographical area & $\begin{array}{l}\text { Tree cover (Area } \\
\text { in sq.km.) }\end{array}$ & $\begin{array}{l}\text { Tree cover (Percent } \\
\text { of GA) }\end{array}$ \\
\hline Delhi & 1,483 & 113 & 7.62 \\
Maharashtra & 307,713 & 9,831 & 3.19 \\
West Bengal & 88,752 & 2,136 & 2.41 \\
& & & 3.59 \\
Tamil Nadu & 130,060 & 4,671 & \\
\hline
\end{tabular}

\section{Phenomenology - cultural perception about issues}

There are factors that give significance to the built environment which are closely related to a person's perception of a place. In philosophical terms, the perceptions of modernity and the resulting architecture and built environment have become the 'crises' of modern architecture (Schulz, 1965). The understanding of a 'place' by people or a set of people is a collective phenomenon that cannot be reduced to single characteristics. The interpretation of 'memory' in environmental knowledge, system of relationships and governance forms cognitive awareness of a physical environment.

Similarly, each community has a sense of its spatial form based on experience, influenced with his current environments. The characteristics of texture, colour, patterns, form and space - needed to orient one in a physical environment may be dependent of the local culture of his social upbringing in the society. An identity and pride is formulated that is formed by inclusivity and participation. The World Summit for Social Development (Copenhagen 1995) has set down some guidelines and recommendations to make inclusive societies that perceive an identity that is common and participatory (Affairs U. N., 2007). India is a culturally diverse country and with globalization and urbanization, the need to embrace a new identity in urban areas have been common. Within this, however, communities still function with diverse knowledge gained by their upbringing and culture. What has ensued is an organic mix of local and global culture with competing aspirations. However, the ideal economical, social and environmentally healthy society has to work to reduce 
this perceived identity of a 'global' identity for a new urban dweller. Most importantly, the common man also brings valuable ecological learnings of his own that if utilised is a resource in the society.

In current dialogues of achieving a global identity, the need for adoption of environmental sustainable attitudes is important. Previous researches have applied this identity achievement and have worked on its potential to achieve sustainable daily behaviours (Swim, et al., 2011).

Environmental psychological studies reveal the importance of human and communal behaviours and their willingness to participate in adopting techniques and methodologies to address climate change issues. Identifying the gaps, therefore, in the perceptions of their natural and structural environments and their understanding of climate change is therefore imperative to know before investing in campaigns and dialogues of climate change.

\section{Knowledge dissemination in community level}

It is important to understand that participatory methods towards addressing various issues with respect to economic, environment and social needs of a community and thereby as a society as a whole has been part of 'culture', especially in India. Many structures and built infrastructure have evolved from such methods of knowledge dissemination through the years and a comparison of traditional and modern knowledge systems have been described below.

\section{Traditional knowledge dissemination}

Traditional knowledge are common in traditional settlements and are based on their social systems of communication. They have 'local, empirical and time tested dynamics' (Council, n.d.). In traditional knowledge systems of knowledge dissemination of information, various techniques are utilized. Some of these include:

- Panchayat discussions

- $\quad$ Kathputli/ puppet shows

- Dance, music and drama forms

- By technical assistance and verbal communication

- By religious rituals

- $\quad$ By medium of painting and handicrafts

Most importantly, the cognitive awareness of the collective community over all matters for survival including social, economic and environmental decisions evolved from a common sense of belonging. The motives and implications of actions developed from 'perception' developed that identified needs to address certain issues. In India, rural areas specially arid regions of Gujarat and Rajasthan developed water conservation structures such as 'baodis' and stepwells that were capable of storing rainwater for the needs of large communities. Many of these structures are still functional among communities and have stood as examples of collective community action towards important decisions of climatic conditions. It is important to note however, that the scale of such communities have not been defined and are beyond the scope of the current study. However, a common character of development has been observed in various scales of community.

Any community can be defined by common socio-cultural dimensions such as the following (Bartle, 2005): 


\author{
1. Technological \\ 2. Economical \\ 3. Political \\ 4. Beliefs and religious \\ 5. Institutional \\ 6. Aesthetic
}

Each of these dimensions of community culture is transmitted by symbols and not genes. They are formed by learned systems and behaviour. Each part however, can change for each individual as he moves away from the system but integrally, is carried as an acquired behaviour. In any community, interactions and communications can be possible by first identifying these dimensions. Table 1 gives brief understanding of these dimensions.

\title{
Modern knowledge dissemination
}

In knowledge dissemination or awareness programs in the contemporary times, qualitative and quantitative methodologies are utilized. Regularly used methods include:

1. Questionnaires and surveys - physical or virtual

2. Focused group discussions

3. Community group discussions and meetings

4. Nonverbal communication such as presentations, photographs, films or documentaries

5. Physical models and drawings

6. Workshops and on-site experiments/ demonstrations

Various previous research done on sustainability have employed these techniques to understand the needs of the general public. In recent experiments across the world where issues of social housing have been addressed, detailed questions in understanding the needs of the society from their economic and physical aspects have been creatively used. Creative use of media in the form of television shows, advertisements etc. have also helped in propagation of cleanliness drives and other social issues. However, the quality of the built environment is still alienated from such discussions. The debates related with environmental activism and planning is held by only certain professionals of the field and a combined decision- making becomes ambiguous. Advocacy of building sustainable neighbourhoods that were even outside the realm of the 'built' infrastructure has been seen in the works of patrons such as Ian McHarg, Patrick Geddes, and Lewis Mumford. The need to institutionalize quality projects was high in a country's development.

The discussion of this paper adopts the principles supporting stakeholder participation in key decisions of the built environment as a social 'pillar' that contributes to environmental, economic and social sustainability (Figure 3). Being home to one sixth of human population in the world, India's social inclusion schemes and programs, can be useful in 'localization' of Sustainable Development Goals (SDGs) all over the world (Ayog \& UN, 2019). To achieve this, a cohesive planning that looks at bridging the gap between all disciplines to be more 'responsive' rather than 'unique' in their action is needed. Moreover, in the midst of these concerns, an organic community keeps building part of the urbanized colonies. 


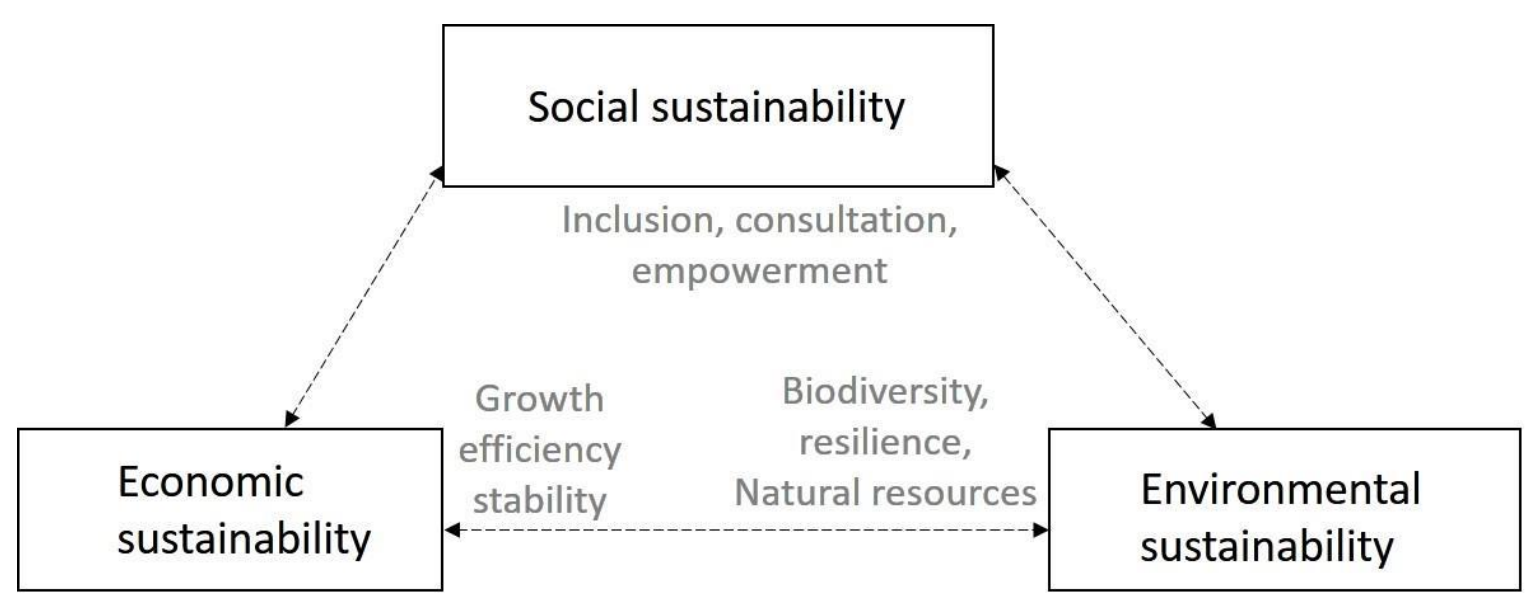

Figure 3 the triad for sustainability based on studies by (Sarr \& Puetmann, 2008) 
[i] Religion : a set of beliefs

[ii] Physical form: an architecture

Certain architectural forms can frame unique meanings
May vary over a range of common God or 'local' Gods [iii] 'symbolic' or 'signs' entities

Certain symbols or signs can indicate or reveal meanings [iv] Texture/pattern
Certain types of patterns or textures can be identified easily for a community [v] Hierarchy
A unique hierarchy in terms of responsibilities, gender, age etc. may be found [vi] Rituals and ceremonies
Religious or other rituals like washing legs before entering house etc. may be followed. [vii] Work
There may be division among the community per their income from work $\begin{array}{ll}\text { [ix] Habits-behavioral pattern } & \text { The movement, the migratory pattern of community, the } \\ \text { seasonal nature of work etc. can affect a being's interaction } \\ \text { with its surroundings }\end{array}$

[x] Community living

\author{
Most importantly, the interaction of the community on a \\ personal level
}

Within various principles of sustainable building, various researchers have supported community participation
in clearly identifying their needs to achieve decisions (Halliday, 2008). The social pillar is seen as a scope for
incorporating 'cultural diversity' (Hill \& Bowen, 1997). Resource efficiency and utilizing principles of ecology
is also seen as backbone for building sustainable built environments (Kilbert, 2008). Research shows that within
India, for many centuries a culture of decentralized participatory decision - making (through village and
community units and leaders) and a careful system of natural resources management formed the basis of
common resource use and conservation strategies. Colonization weakened these bonds of social relationships
and community management systems (Gadgil \& Guha, 1992). The British capitalized on the items and made the
process follow jurisdiction by controlling the natural resources of state (Ganguly, 2016). This is common
practice in the country today which discourages the act of social participation in the management of resources.
However, the design community across the world, have identified that the environment is managed better when
citizens are active and involved with creation and management. In this regard, the first attempt to explore user
participation in design process was held in an international conference in 1971 (Lee, 2016). Various works of 
eminent architects who have won prestigious awards in the field have involved the public in design. The importance of the government initiatives and schemes are highlighted and a collaborative effort to bring resources available to the public is achieved. However, the role of the citizen in maintaining and making sustainable choices thereafter is a gap which as mentioned by environmental psychologists, is a behavioural change in lifestyle.

Also, as mentioned before, the role of community is of paramount in the management of resources by the roles that are defined in the dimensions of their community. By nature, every individual perceives issues of the built environment, urbanization and climate change by his own phenomenological values. In an urban scenario, the need to conform to the 'global identity' although needed, has put pressure on the uses of resources due to undefined roles and unrecognized responsibilities of the agents of a community or the participants of a nation as a whole. Therefore, the need for recognizing their roles as well as being involved in the decisions that influence their built environment through a common platform is seen as an 'ideal' initiative. Support from mobilized local government in the city and the recognition of their vernacular built form as an educational initiative is seen as a 'resilient' measure for sustainable growth. Within this, understanding the aspirations of other bodies of professionals for a comprehensive planning would open opportunities for dialogue and interaction for participating bodies. Such an initiative, though 'ideal' is not an alien concept in the developed countries where certain centres have worked towards achieving public awareness and the role of architecture in society. Architectural research and fostering of innovative practices have been taken up. Educational institutions have also been involved in the process for young students to learn of the built environment from a young age. Families and neighbourhood involvements are also users to the institute.

\section{Data Collection and analysis technique}

Surveys are reliable tools for reporting ideas and behaviour of the respondents with respect to certain hypothesis (Alwin \& Krosnick, 1991). A public survey was conducted using online method regarding the built environment as shown in Table 3. The participants were urban dwellers from New Delhi, Bangalore, Mumbai, Kochi and Kolkata residing for more than 15- 20 years. The intention of looking at this demographic of respondents were with the assumption that they will be acquainted with the built environment issues of the city. The incomes based on their professions (as stated in results) were found to be middle-class which is the major urban dwelling population as per 2016 GNI per capita of India (Nations, 2019). A total of 170 respondents participated in the month-long survey. $60 \%$ of the respondents were women with majority being working in the cities in varied professions. The questions were structured to receive statistics to three hypothesis involving the literature studied in this study. These were -

(i) Category 1 - To understand their acquaintance with the field of architecture

(ii) Category 2 - To understand their interest to learn about the built environment and participate in sustainable living

(iii) Category 3- To understand the perception of the role of building materials in construction

Within these three broad categories of hypothesis, 15 statements were asked to the respondents, including their gender and professional backgrounds. There were questions to which their agreement and disagreements were mapped, while some questions noted the degree of knowledge about that particular subject (Table 2). The survey data was then compiled in the form of graphs and percentages. Further, inferences were made about the questions that were most answered in detail.

The sequence of questions based on the three categories included their familiarity with architects/ architecture and built environment (Statement 03 and Statement 04), the perception of technological advancements in built 
environment and traditional and vernacular building knowledge (Statement 05),climate change and relationship to building and planning techniques (Statement 07 and Statement 08), resilience and influence of green open spaces (Statement 09), eagerness to involve in learning of built environment and sustainable living ( Statement 06, Statement 07 and Statement 11), understanding of the complexity of the built environment (Statement 12), preferable activities that would help in learning about architecture design and the built environment in a public atmosphere (Statement 13), interest in activities that will help improve the quality of built environment in their own environments (Statement 14 and 15).

The statements of the survey were drafted from paraphrasing literature of the relevant topics within the context of India. This is evident in questions regarding the choice of materials in building, the notion of 'resilience' in an urban setting and the scope of open green spaces improving the health of the city.

Statement 3 had options between ' 01 ' to ' 05 ' where 1 denoted the highest knowledge of the subject. Statements $4,5,6,9,10,11,14$ and 15 were responses to 'yes', 'no' and 'maybe'. An arithmetic mean close to 'yes' meant most respondents agreed with the statement. The arithmetic mean calculation was achieved by the total score for

\begin{tabular}{lll}
\hline Category & Statement order & Statements
\end{tabular}

that statement divided by the number of respondents. Statements 13, 12 and 8 had multiple choices to respond based on personal preferences.

\section{Survey Results}

$60 \%$ of the respondents were women whereas $40 \%$ were male. Only $8 \%$ were from an architecture background, $32 \%$ were students from other backgrounds and the rest were professionals from varied fields, most notablyteachers, journalist, content artist, advertising professional, engineers, legal employees etc.

Category $01-28.4 \%$ of the respondents rate their knowledge of architects to be excellent. The majority which was $30.8 \%$ responded it to good whereas the others rated it to be average and poor. Only $18.9 \%$ of the respondents could define the terms 'built environment'. $39.6 \%$ were willing to guess and $45 \%$ said they will have to do an online search for the same. $1.8 \%$ of the people were not interested to know about it.

Category $02-60.9 \%$ of the respondents were interested in architecture whereas $14.8 \%$ were not. $24.3 \%$ of people weren't sure about their interest in architecture design and built environment. $76.3 \%$ of respondents strongly believed that an open platform to explore the idea of architecture, design and sustainable living would interest them. 58\% of the respondents agreed that stricter planning and building technologies could have mitigated the impact of the floods in various parts of the country. $91.1 \%$ of respondents agreed that open green spaces could improve the resilience of cities. However, $8.9 \%$ still weren't sure of such a claim. $91.1 \%$ were concerned of the lack of proper urban drainage and the impact of flooding on the less resilient sites. $2.9 \%$ of the respondents didn't agree that proper infrastructure would improve urban flooding scenes. The rest $6 \%$ of the respondents were unsure of the claim as shown in Figure 4.

Category 3- While $34.9 \%$ of the respondents believed that technological advancements in the field of building materials will improve the quality of the environment (built and unbuilt),

Table 3- Survey Questions (Author) 


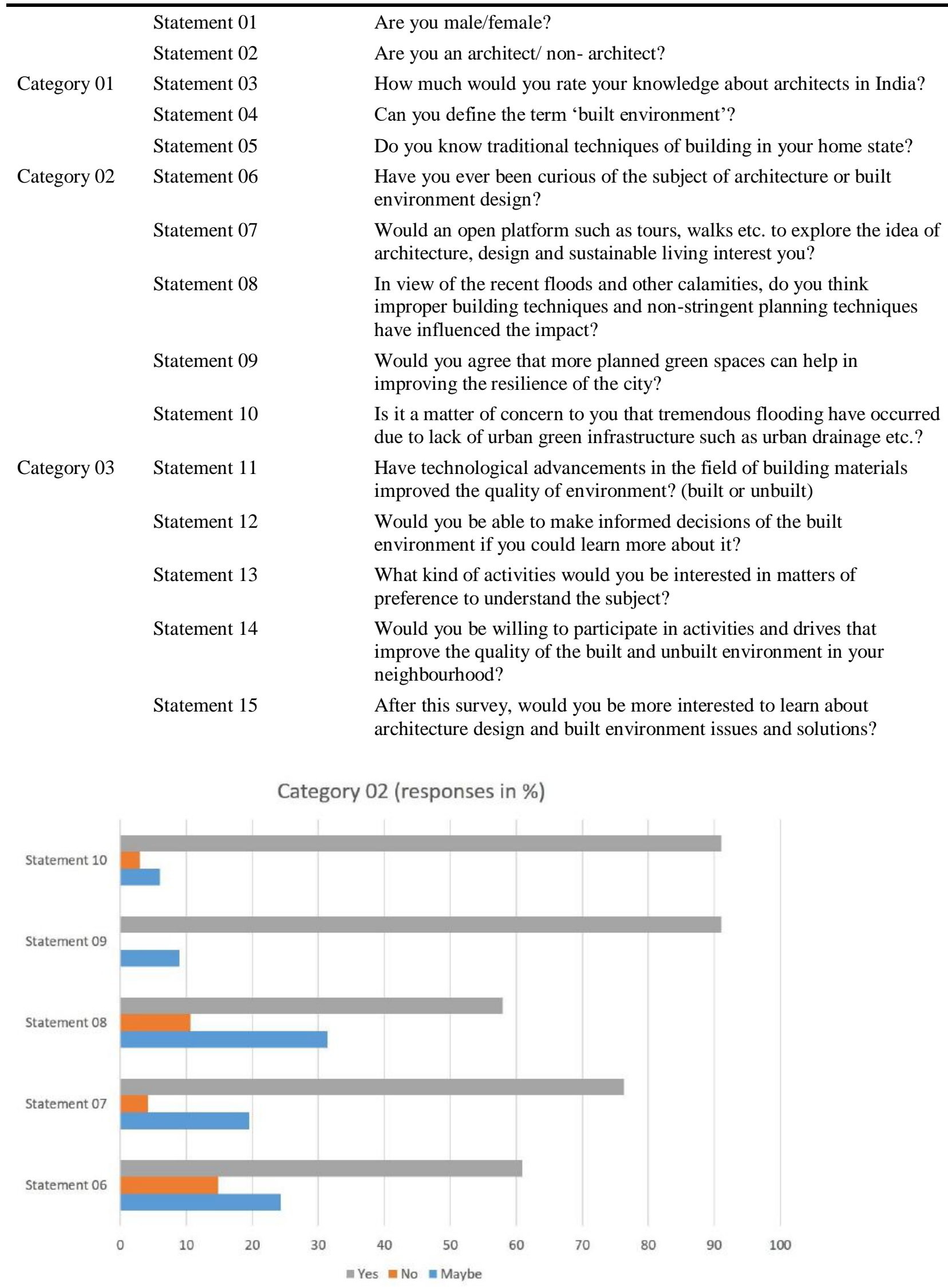


Figure 3 Responses to Category 2 statements (in percentage)

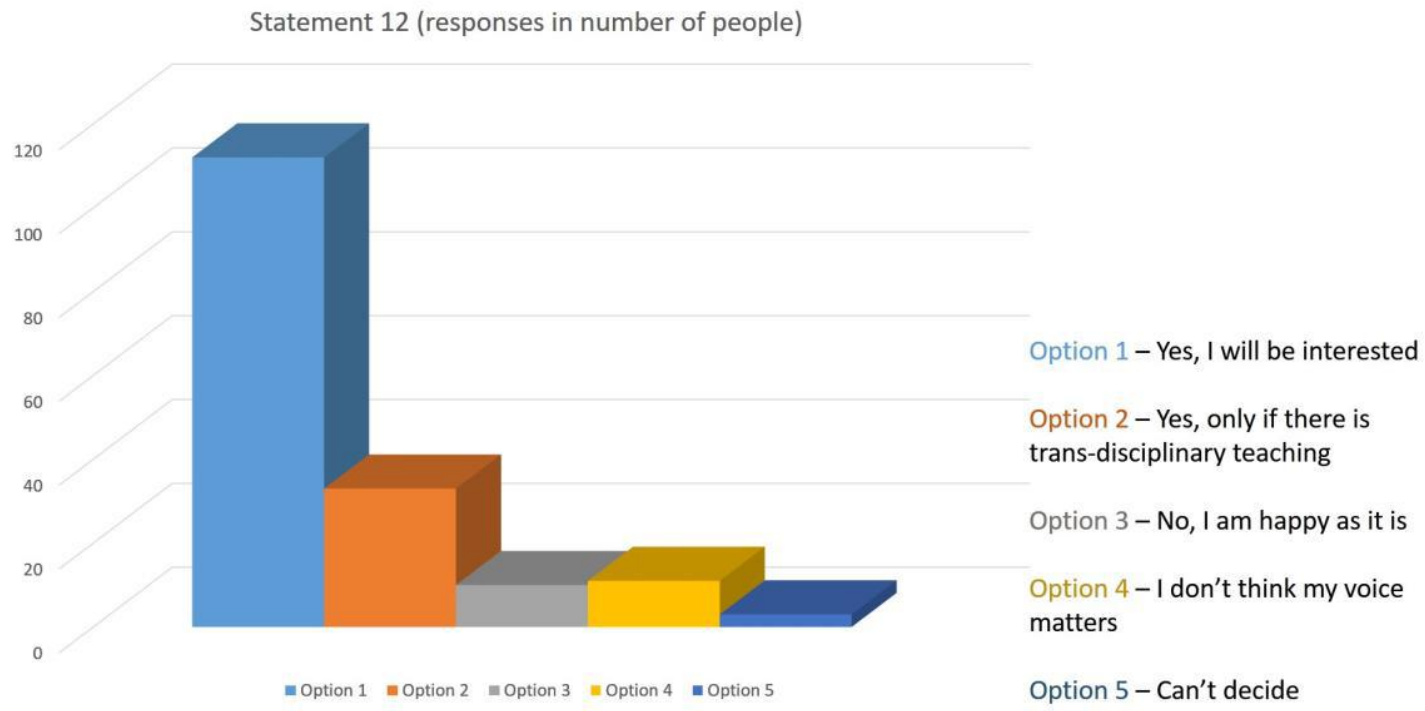

Figure 4 Statement 12 about learning about built environment

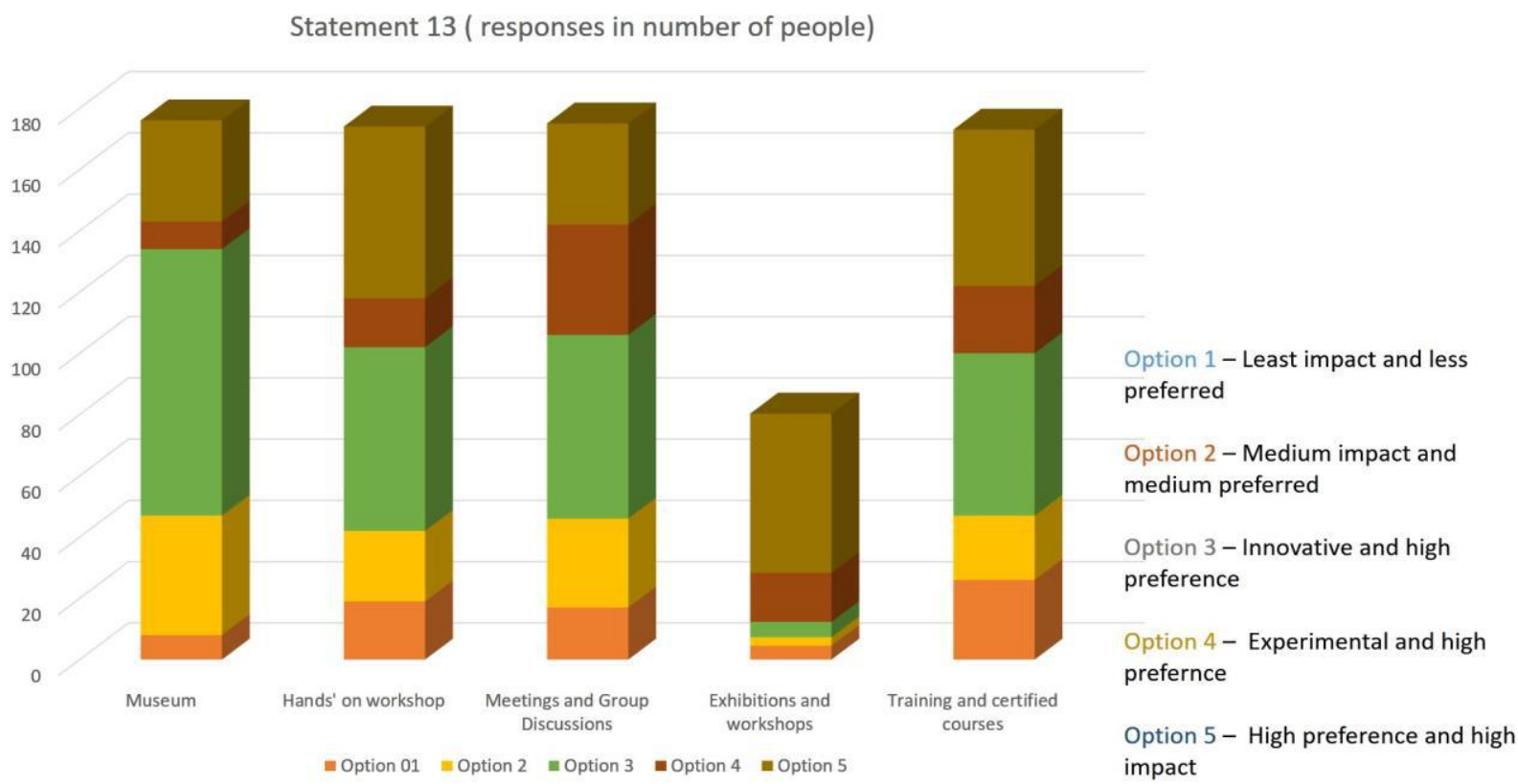

Figure 5 Statement 13 about activities to learn about built environment according to preferences

$24.3 \%$ weren't sure but were interested to know. Also, $17.8 \%$ responded positively to the option of technology consuming most energy in comparison to traditional materials and preferring the former over the latter. At the same time, $21.9 \%$ of the respondents said that the question was very subjective and couldn't come to any conclusion (Figure 5). 
Statement 13 focused on knowing the kind of activities that such a platform could provide. The nature of activities are based on the type of work done by professionals and the facilitators across the world. Some institutes have also worked extensively in just one of these options. However, since it could vary in an urban setting, especially which of Indian cities, a general survey was aimed to know their perception of such activities and its resulting impact.

As discussed, this is a mixture of traditional knowledge dissemination and modern dissemination techniques to appeal to all masses of the society (Figure 6).

\section{Detailed discussion of Statement 13 and results}

Statement 13 mentions the following activities and the responses are noted as follows. Each activity was associated with 4 responses in which ' 01 ' was for 'least impact' and less preferred, '02' was for 'medium impact' and medium preferred, '03' was for 'innovative option and higher preference', '04' was for 'experimental but preferable' and option ' 05 ' with 'highest preference and impact'.

- Museums -8 people responded with option 01, 39 with option 02, 87 of them responded with option 03, 9 responded to option 04 and 33 responded with option 05 . The general response shows preference to this option.

- Hands'- on workshops - 19 people responded with option 01, 23 responded with option 02, 60 people responded with option 03,16 responded with option 04 and 56 responded to option 05 . The general response was uniform and responded as being the most preferred and impactful activity.

- Meetings and group discussions - 17 responded with option 01, 29 with option 02, 60 with option 03, 36 with option 04 and 33 with option 05 . This option had medium impact and medium preference.

- $\quad$ Exhibitions and workshops - 7 responded with option 01, 29 with option 02, 69 responded with option 03,16 responded with option 04 and 52 responded with option 05 . The activity had high impact and preference.

- Training and certified courses - 26 responded with option 01, 21 responded with option 02, 53 responded with option 03,22 with option 04 and 51 with option 05 . The responses were uniform for all options and could be preferable but with medium impact.

Further, in statement $14,54.4 \%$ responded that they will be interested in participating in activities that would improve the built environment quality of their neighbourhood.

\section{Discussion and Conclusion}

Built environment and sustainability are vast spectrums of study and the perception about them are also influenced by the acquired learning as discussed in the phenomenological perspective. Also, in the traditional technique of passing on knowledge, various dimensions of community are involved. The techniques used in the modern technique of knowledge dissemination would require learning about this perception and way of communication. Regarding the quality of the built environment, the survey conducted among the urban dwellers have shown a growing interest in knowing about the built environment and architecture which is invariably a part of it. The general opinion also suggested at improving lifestyle choices to achieve this goal. A majority of the actions and activities that centered on user participation of the general public were noted to be of high preference indicating the impact it could make if it were taken up. The value of the study lies in the transdisciplinary action that requires multiple stakeholders to be aware of and equally informed of the issues surrounding the built environment which directly impact the environment as a whole. As previous and ongoing 
studies have shown, creating an active environment for learning about the profession as a tool for sustainability can be a major influence on lifestyle choices of all sections of society alike. An accessible platform for such a discussion has been discussed and surveyed in the study. However, the scope for identifying the organizational and structural aspect of such a space is vast and is an area that needs further research. Also, the detailed role of organizations and professions that can ally with and benefit from such an arrangement in the overall education of the general public is also an interesting area to be covered.

\section{Acknowledgement}

I thank my professors for their insights as well as for private review of the paper. I also thank friends, family and the Almighty for being my constant support.

\section{References}

Affairs, M. o. (2019). Handbook of Urban Statistics. New Delhi: Government of India.

Affairs, U. N. (2007). Final report on the expert group meeting on creating an inclusive society : practical strategies to promote social integration. Paris, France: Division of Social Policy and Development.

Alwin, D., \& Krosnick, J. (1991). The Reliability of Survey Attitude Measurement. Sociological Methods and Research, 139-181.

Ayog, N., \& UN. (2019). Localising SDGs- Early Lessons from India. New Delhi.

Bartle, D. P. (2005, 01 29). Community Empowerment Collective. Retrieved from What is a community: www.cec.vcn.bc.ca

Bhalla, P., \& Bhattacharya, P. (2015). Urban Biodiversity and Green Spaces in Delhi: A Case study of new settlement and Lutyen's Delhi. Journal of Humanities and Ecology, 83-96.

Chhaya, H. D. (2004). Profession, Education and Regulatory Bodies in India: a theme paper towards a national dialogue. Architecture + Design India.

Council, A. S. (n.d.). www.astec.gov.in. Retrieved from http://www.astec.gov.in/ncsc/agb_5_tks.pdf

ENVIS Center on Human Settlement's. (2018). Retrieved from ENVIS Center on Human Settlement's: http://www.spaenvis.nic.in/index2.aspx?slid=2951\&sublinkid=1832\&langid=1\&mid=4

Gadgil, M., \& Guha, R. (1992). The Fissured Land. Oxford University Press.

Ganguly, S. (2016). Deliberating environmental policy in India: Participation and the role of advocacy.

Guillaud, \& Houben. (1994). Earth Construction : a Comprehensive Guide. 13.

H. Buchanan, A., \& Honey, B. (1994). Energy and carbon dioxide implications of building construction. Energy and Buildings, 205-217.

Halliday, S. (2008). Sustainable Construction. Butterworth Heinemann.

Hill, R., \& Bowen, P. (1997). Sustainable construction : Principles and a framework for attainment. Construction Management Economy, 223-239.

India, F. S. (2017). Indian State of Forest Report. Government of India.

Kilbert, C. (2008). Sustainable Construction: Green Building Design and Delivery. NJ, USA: John Wiley and Sons.

Kumar, A., \& Singh, D. (2017). Built Environmental Issues in India and an Approach to Mitigation. International Journal on Emerging Technologies.

Lee, Y. (2016). Design Participation Tactics: Redefining User Participation in Design. Design Research Society: International Conference. Lisbon.

Manjunath, N. (2015). Contemporary Bamboo Architecture in India and its Acceptability. 10th World Bamboo Congress, Korea 2015, (pp. 1-17).

McPherson, G., \& Simpson, J. (1999). Carbon Dioxide Reduction through Urban Forestry: Guidelines for Professionl and Volunteer Tree Planters. California: Pacific Southwest Research Station. 
Nations, U. (2019). World Urbanization Prospects 2018 Revision. New York: United Nations.

Sagheb, Vafaeihosseini, \& Ramancharla. (2011). The Role of Building Construction Materials on Global Warming Lessons for Architects. Hyderabad: Centre for Earthquake Engineering International Institute of Information Technology.

Sarr, D. A., \& Puetmann, K. J. (2008). Forest management, restoration and designer ecosystems : Integrating strategies for a crowded planet. Ecoscience, 17-26.

Schulz, C. N. (1965). Intentions in Architecture. Cambridge: MIT press.

Services, U. D. (2006, February). Obesity and the Built Environment. Retrieved from http:// grants.nih.gov/grants/guide/rfa-files/RFA-ES-04-003.html

Swim, J., Stern, P., Doherty, T., Clayton, S., Reser, J. W., \& Howard, G. (2011). Psychology's Contributions to Understanding and Addressing Global Cimate Change. American Psychologist, 24-250. 